\title{
СОВЕРШЕНСТВОВАНИЕ ОРГАНИЗАЦИИ ТРУДА ГОСУДАРСТВЕННЫХ И МУНИЦИПАЛЬНЫХ СЛУЖАЩИХ
}

\section{IMPROVING THE ORGANIZATION OF WORK OF STATE AND MUNICIPAL EMPLOYEES}

\section{Zakharova}

Summary. In Russia, although the constitutional foundations of the civil service as a mechanism of state management have developed, which is radically different from the Soviet system of management, but a unified regulatory legal framework for regulating public-service relations has not yet been created. In addition, public service at the federal level and at the level of the subjects of the Russian Federation was carried out as a service in a separate state body, which was unacceptable for effective public administration.

Today, the organizational foundations of the municipal service are of great importance in modern Russia. One of the aspects is the analysis and improvement of the organization of labor of employees in municipalities. The paper analyzes the possibilities of improving the labor efficiency of municipal employees of the administration of the city district "Kaliningrad City".

Taking into account the problems of the chosen research topic, it is necessary to determine the directions for improving the organization of work of state and municipal employees. The study is based on the hypothesis that the improvement of the organization of work of state and municipal employees is influenced by such factors as the reform of the civil service of the Russian Federation, the peculiarities of the organization and regulation of labor, as well as the responsibility of state and municipal employees.

The article examines the system of the civil service of the Russian Federation, the problems of its regulation and improvement, defines the basic principles of building and reforming the system of the civil service of the Russian Federation, identifies modern problems arising in the organization of labor relations of civil servants, and determines the directions of their improvement, defines the features of the organization and regulation of the work of municipal employees, touches on the principles of the organization and functioning of the municipal service in the Russian Federation, suggests ways to improve the organization of the work of municipal employees, characterizes the disciplinary and administrative responsibility of state and municipal employees, touches on the issues of conflict of interests in the state and municipal service, determines the mechanism of overcoming it.

Keywords: civil service, municipal service, labor efficiency, improvement of labor organization, civil servants, municipal employees, principles of public service, management organization, official relations, legal regulation.

\author{
Захарова Виктория Алексеевна \\ К.ю.н., доцент, АНОО ВО «Калининградский \\ институт управления» \\ zhan.e@bk.ru
}

Аннотация. В России хотя и сложились конституционные основы государственной службы как механизма управления государством, кардинально отличающегося от советской системы управления, но единая нормативная правовая база регулирования государственно-служебных отношений все же не была создана. К тому же государственная служба и на федеральном уровне, и на уровне субъектов РФ осуществлялась как служба в отдельном государственном органе, что было недопустимо для эффективного государственного управления.

На сегодняшний день большое значение в современной России приобретает организационные основы муниципальной службы. Одним из аспектов является анализ и совершенствование организации труда служащих в муниципальных образованиях. В работе проанализированы возможности повышения эффективности труда муниципальных служащих администрации городского округа «Город Калининград».

С учетом проблематики выбранной темы исследования необходимо определить направления совершенствования организации труда государственных и муниципальных служащих. В основу исследования положена гипотеза 0 том, что на совершенствование организации труда государственных и муниципальных служащих влияют такие факторы, как реформирование государственной службы РФ, особенности организации и регулирования труда, а также ответственность государственных и муниципальных служащих.

В статье исследуется система государственной службы РФ, проблемы ее регулирования и совершенствования, определяются основные принципы построения и реформирования системы государственной службы РФ, выявляются современные проблемы, возникающие при организации трудовых отношений государственных служащих, и определяются направления их совершенствования, определяются особенности организации и регулирования труда муниципальных служащих, затрагиваются вопросы принципы организации и функционирования муниципальной службы в РФ, предлагаются пути совершенствования организации труда муниципальных служащих, дается характеристика дисциплинарной и административной ответственности государственных и муниципальных служащих, затрагиваются вопросы конфликта интересов на государственной и муниципальной службе, определяется механизм его преодоления.

Ключевые слова: государственная служба, муниципальная служба, эффективность труда, совершенствование организации труда, государственные служащие, муниципальные служащие, принципы государственной службы, организация управления, служебные отношения, правовая регламентация. 
A ктуальность исследования обусловлена тем, что государственная служба играет важную роль в реализации заложенных Конституцией РФ принципов и задач государственного управления, в ч. 4 ст. 32 которой в качестве одной из важнейших форм участия граждан в управлении делами государства и общества определена государственная служба.

Формирование законодательства о государственной службе было обусловлено быстрыми темпами организации и преобразования системы органов исполнительной власти, механизмов государственного управления, потребностью в совершенствовании институтов контроля, государственного принуждения и воздействия.

В первую очередь необходимо выделить конституционно-правовые основы реформирования системы государственной службы РФ. В России должна была быть создана новая, значительно расширенная и измененная нормативная база государственной службы, состоящая из Конституции РФ, ряда федеральных законов и значительного числа подзаконных нормативных правовых актов, а также актов субъектов РФ.

Одним из существенных инструментов в подборе кадров является оценка трудовой деятельности кандидата на должность муниципального служащего, которая служит основой для принятия кадровых решений при отборе, продвижении, формировании резерва на замещение должностей различных уровней, при определении важнейших направлений переподготовки и повышения квалификации. Особенности организации труда муниципальных служащих, направления ее совершенствования рассмотрены в статье на примере Администрации Городского округа «Город Калининград».

На сегодняшний день большое значение в современной России приобретает организационные основы муниципальной службы. Одним из аспектов является анализ и совершенствование организации труда служащих в муниципальных образованиях. В работе проанализированы возможности повышения эффективности труда муниципальных служащих администрации городского округа «Город Калининград».

Реализация концепции административной реформы, направленной, на формирование государственного аппарата новейшего типа, осуществляется уже полтора десятка лет, а дискуссия по поводу отраслевой принадлежности правоотношений по прохождению государственной службы не утрачивает своей остроты. В рамках реализации концепции очевидно обозначилась тенденция к обособлению правового регулирования государственной службы от регламентации иных видов профессиональной деятельности, формированию так называемого института «служебного права», в основе которого заложены исключительно или преимущественно публично-правовые механизмы воздействия. Данная идея имеет как многочисленных сторонников, так и противников, проблема сущностной природы государственной службы уже многие годы активно обсуждается в юридической науке, является предметом научных исследований ученых-трудовиков, специалистов в области государственного и административного права. Вопросам совершенствования организации труда государственных и муниципальных служащих посвящены многие исследовательские работы, в которых объектом научных исследований являются государственные гражданские и муниципальные служащие, в частности - работы Войтович В.Ю., Ворониной Л.И., Заборовой Е.Н., Карякина А.М., Охотского Е.В., Петрова В.И.

Таким образом, целесообразность разработки темы обусловлена необходимостью дальнейшего изучения реализации компетентностного подхода к проблеме совершенствования организации труда государственных и муниципальных служащих, разработки проектных рекомендаций по ее совершенствованию.

С учетом проблематики была определена следующая цель исследования: определить направления совершенствования организации труда государственных и муниципальных служащих.

Научная новизна исследования заключается в ключевых положениях, которые раскрываются в статье, и направлены на практическое применение теоретических результатов исследования в деятельности Администрации ГО «Город Калининград».

\section{Цель исслеАования}

Определить направления совершенствования организации труда государственных и муниципальных служащих.

Задачи исследования:

- исследовать систему государственной службы РФ: проблемы регулирования и совершенствования;

- определить основные принципы построения и реформирования системы государственной службы РФ;

- выявить современные проблемы, возникающие при организации трудовых отношений государственных служащих и направления их совершенствования;

- определить особенности организации и регулирования труда муниципальных служащих; 
- рассмотреть принципы организации и функционирования муниципальной службы в РФ;

- предложить пути совершенствования организации труда муниципальных служащих;

- охарактеризовать дисциплинарную и административную ответственность государственных и муниципальных служащих;

- рассмотреть конфликт интересов на государственной и муниципальной службе и определить механизм его преодоления.

Теоретическая значимость заключается в расширении научных представлений об организации труда государственных и муниципальных служащих. Результаты исследования дополняют существующие сведения об организации труда государственных и муниципальных служащих.

Практическая значимость данного исследования заключается в возможности использования результатов исследования в условиях подготовки руководителей, а также в процессе консультирования по оптимизации организации труда государственных и муниципальных служащих.

Для решения поставленных задач были использованы следующие методы: анализ нормативных правовых документов, анализ теоретической литературы, сравнительный анализ, статистический анализ.

Принципы государственной службы можно определить как основополагающие идеи, установления, требования, которыми руководствуются государственные служащие в ходе своей профессиональной деятельности. В них выражены необходимые основания функционирования государственного аппаратного управления [1].

Согласно общепринятой классификации принципов государственной службы выделяют три их вида:

Конституционные принципы отражают принципы организации и деятельности государства и его органов, нашедших закрепление в нормах Конституции РФ.

Организационные (специальные) принципы определяют механизм функционирования и построения звеньев государственного аппарата [2].

Профессиональные (технологические) принципы определяют механизм и процедуры прохождения государственной службы, служебной деятельности и поведения государственных служащих.

При организации управления в сфере государственной службы необходимо базироваться на исходных по- ложениях - принципах, которые представляют собой сплав опыта, накопленного в данной сфере и теоретических положений и обобщений. Рассмотренные принципы являются базовыми нормативными правовыми положениями для реализации государственной службы [3]. На современном этапе они должны непременно учитываться при разработке специального законодательства о государственной службе и реально воплощаться на всех уровнях государственной власти.

Целостной системы правового регулирования служебных отношений на государственной гражданской службе, о которой было заявлено в Концепции реформирования государственной службы, не получилось. Регулирование служебных отношений на государственной гражданской службе осуществляется сегодня наполовину нормами закона, переписанными из ТК РФ, а наполовину - путем применения норм ТК РФ субсидарно.

\section{Результаты исслеАования}

На основании изученных источников можно сделать вывод, что в настоящее время в сфере совершенствования организации труда государственных и муниципальных служащих можно выявить следующие проблемы и определить пути их решения:

\section{Проблема}

Сегодняшний выбор средств правовой регламентации отношений по прохождению государственной службы не является оптимальным [4]. Механическое заимствование конструкций трудового права, очевидно, не даст нужного регулятивного эффекта в условиях построения новой модели регулирования служебных отношений. Вместе с тем, возможности для использования частноправовых методов правовой регламентации государственной службы не исчерпаны. Полный отказ от них приведет к чрезмерно упрощенному подходу к правовой организации служебной деятельности, что неизбежно скажется как на общем уровне обеспечения прав и свобод человека и гражданина в нашей стране, так и на эффективности государственного управления.

\section{Путь решения}

Одним из существенных инструментов в подборе кадров является оценка трудовой деятельности кандидата на должность муниципального служащего, которая служит основой для принятия кадровых решений при отборе, продвижении, формировании резерва на замещение должностей различных уровней, при определении важнейших направлений переподготовки и повышения квалификации. 


\section{Проблема}

Острой проблемой остается незначительный оперативный резерв на руководящие должности муниципальной службы.

\section{Путь решения}

Проблема резерва кадров на муниципальную службу может быть решена на основе добровольного волеизъявления граждан, решениями конкурсных комиссий [5]. Резерв должен формироваться из числа наиболее компетентных и профессионально подготовленных муниципальных служащих, а также лиц, не состоящих на муниципальной службе, потенциал которых может быть использован более эффективно. В этом направлении предстоит решать следующие задачи:

- совершенствование нормативной и методической базы;

- выявление количественной и качественной потребности в оперативном и стратегическом резерве кадров на муниципальную службу;

- выявление через конкурсный отбор специалистов и руководителей, имеющих соответствующий потенциал для зачисления в резерв, в т.ч. на руководящие должности;

- разработка и реализация плана подготовки резерва кадров на муниципальную службу в органах муниципального самоуправления ГО «Город Калининград» [6].

\section{Проблема}

Основным демотивирующим фактором организации труда муниципальные служащие считают низкий уровень денежного содержания.

Дефицитные муниципальные бюджетов не позволяют в полной мере использовать материальные стимулы [7].

\section{Путь решения}

В этом случае упор необходимо делать на стимулы нематериального характера. В качестве таких мер могут применяться: конкурс для определения лучшего служащего и введение почётных званий, например, «Лучший муниципальный служащий месяца (квартала, полугодия, года)»; соревнования между структурными подразделениями по достижению наилучших значений показателей своей деятельности; мероприятия по сплочению коллектива (спортивные соревнования, творческие встречи); поддержка здорового образа жизни муниципальных служащих (организация занятий в спортивных залах, бассейнах); публичное вручение почетных грамот и благодарностей за добросовестное выполнение своих обязанностей; обед с руководителем администрации, на котором сотрудник может поделится своими предложениями и планами по работе. Целесообразно использовать газету «Гражданин», чтобы отметить разовые или систематические, индивидуальные или коллективные успехи служащих.

\section{Проблема}

Значение недопущения конфликта интересов предотвращение и урегулирование его в любой сфере деятельности, где имеют место коррупционные риски, выполняет важную профилактическую функцию [8]. Конфликт интересов реализуется путем использования полномочий должностными лицами. Однако, на сегодняшний день не существует эффективного и отлаженного механизма профилактики коррупционных рисков.

\section{Путь решения}

Профилактика коррупционных рисков, приводящих к конфликту интересов, может и должна осуществляться в следующих превентивных мерах:

- регламентация административных, экономических и иных процедур, контроль за их исполнением;

- гласность и открытость итогов оценочных мероприятий, конкурсов, рейтингов и т.п.;

- квалифицированный отбор сотрудников в структуры, принимающие ответственные решения;

- сокращение служебных контактов сотрудников без необходимости;

- использование аудио- и видеоконтроля в целях выявления нарушений регламентов и процедур;

- своевременное перераспределение обязанностей для недопущения выстраивания противоправных отношений.

Причем закон возлагает обязанность это сделать на само должностное лицо, попавшее в эту ситуацию и могущее еще разрешить этическую проблему правовыми процедурами, и тем самым достигается экономия репрессий, замена их более мягкими мерами в пользу сознательной корректировки поведения. Таким образом, у сотрудников формируется контроль, осмотрительность и ответственное отношение к своему поведению, а также поведению членов семьи, предвидение и недопущение отступлений от должностных правил поведения в будущем.

\section{Проблема}

Не имеется единой нормативной базы в сфере регулирования труда гражданских служащих, что ведет к возникновению противоречий и пробелов между региональными и федеральными нормами в части гражданской службы [9]. 


\section{Путь решения}

На наш взгляд, могут быть предприняты следующие меры, направленные на решение ситуации:

- разработать и утвердить единый регламентированный механизм принятия регионального законодательства в сфере регулирования трудовой деятельности государственных гражданских служащих;

- определить сроки для устранения противоречий, выявленных на практике между региональным и федеральным законодательством о государственной службе;

- исключить неоднозначность понимания терминов при принятии новых актов путем использования общепринятых понятий;

- активнее внедрять практику участия на безвозмездной основе в аттестации государственных гражданских служащих независимых экспертов, в том числе экспертов в области права, представителей высших учебных заведений. Доля указанных экспертов в комиссии должна составлять не менее $35 \%$. Данный механизм позволит дать объективную всестороннюю оценку кандидата на замещение должности государственной гражданской службы еще на этапе предварительного отбора и привлекать на государственную службу только высококвалифицированных, грамотных специалистов.

\section{Проблема}

Несмотря на солидную нормативную базу, регулирующую муниципальную службу, работа с резервом кадров, особенно руководящего состава органов муниципального самоуправления в ГО «Город Калининград», еще не стала системно организованной. Острой проблемой остается незначительный оперативный резерв на руководящие должности муниципальной службы [10].

\section{Путь решения}

Проблема резерва кадров на муниципальную службу может быть решена на основе добровольного волеизъявления граждан, решениями конкурсных комиссий. Резерв должен формироваться из числа наиболее компетентных и профессионально подготовленных муниципальных служащих, а также лиц, не состоящих на муниципальной службе, потенциал которых может быть использован более эффективно. В этом направлении предстоит решать следующие задачи:

- совершенствование нормативной и методической базы;

- выявление количественной и качественной потребности в оперативном и стратегическом резерве кадров на муниципальную службу;
- выявление через конкурсный отбор специалистов и руководителей, имеющих соответствующий потенциал для зачисления в резерв, в т.ч. на руководящие должности;

- разработка и реализация плана подготовки резерва кадров на муниципальную службу в органах муниципального самоуправления ГО «Город Калининград».

\section{Проблема}

Институту дисциплинарной ответственности на государственной и муниципальной службе объективно требуется правовой механизм недопуска туда лиц, уволенных за совершение определенных дисциплинарных проступков (не обязательно коррупционных, хотя и в том числе), своеобразная «дисциплинарная дисквалификация».

\section{Путь решения}

С нашей точки зрения, заслуживает поддержки предложение А.А. Гришковца [11] о введении в законодательство в качестве самостоятельной санкции такого дополнительного дисциплинарного взыскания, как «лишение права замещать должности государственной гражданской службы». Если основное взыскание в виде увольнения будет налагать сам представитель нанимателя, то дополнительное должен налагать суд, куда он может обратиться с соответствующим представлением» [12].

\section{Проблема}

Дисциплинарная ответственность по частоте применения традиционно доминирует среди других видов юридической ответственности государственных служащих. Вместе с тем крайне низкий эффект от ее применения не позволяет достичь должного уровня исполнительской дисциплины в системе государственного управления, что, в свою очередь, требует выяснения причин подобного положения и определения путей их устранения.

\section{Путь решения}

Полагаем, слагаемыми эффективности дисциплинарной ответственности в системе государственной службы должны стать: 1) эффективность правового регулирования; 2) эффективность правоприменительной деятельности. Помимо слагаемых эффективности, существуют влияющие на них факторы [13], к числу которых необходимо отнести: 1) правосознание и правовую культуру государственных служащих и субъектов дисциплинарной юрисдикции; 2) состояние служебной дисциплины в аппарате государственных органов. 


\section{Проблема}

В случаях, когда деяние государственного либо муниципального служащего представляет собой одновременно и административное правонарушение, и дисциплинарный проступок, на уровне законодательной стратегии необходимо определить, какой вид юридической ответственности будет в большей степени способствовать достижению ее целей.

\section{Пути решения}

Путей решения данной проблемы несколько:

- необходимо идти по пути большей формализации составов дисциплинарных проступков, закрепляя в законодательстве те из них, ответственность за которые должна наступать независимо от желания представителя нанимателя;

- дискреционные полномочия представителя нанимателя (работодателя) должны быть существенно уменьшены лишь в отношении дисциплинарных проступков, имеющих публичный характер, непосредственно посягающих на надлежащее функционирование государственной и муниципальной службы. В отношении же дисциплинарных проступков, посягающих лишь на правила внутреннего служебного распорядка, дискреционные полномочия вполне могут быть сохранены [14], хотя и применительно к ним повышение публичности и гласности при реализации субъектом дисциплинарной власти своих полномочий заслуживает поддержки.

Государственные и муниципальные служащие, совершившие определенные административные правонарушения, не просто увольняются со службы в связи с дисквалификацией, но и не могут в течение определенного срока быть приняты туда вновь.

\section{Проблема}

Законодательство о большинстве видов государственной и муниципальной службы не предусматривает четкого и однозначного запрета на прием на службу лиц, уволенных в связи с утратой доверия. Законодатель увязал утрату доверия со взаимоотношениями гражданского служащего и конкретного представителя нанимателя [15].

\section{Путь решения}

Необходимо ввести в законодательство в качестве самостоятельной санкции такого дополнительного дисциплинарного взыскания, как «лишение права замещать должности государственной гражданской службы». Если основное взыскание в виде увольнения будет налагать сам представитель нанимателя, то дополнительное должен налагать суд, куда он может обратиться с соответствующим представлением».

\section{Проблема}

Среди безотлагательных проблем кадровой работы в системе муниципальной службы ГО «Город Калининград» является проблема замещения вакантных должностей муниципальной службы. Проблема конкурсного отбора на муниципальную службу в ГО «Город Калининград» тесно увязана с проблемой формирования кадрового резерва на муниципальную службу.

Аттестация и проводимая работа по оптимизации структуры органов муниципального самоуправления обнаружили ряд недочетов, связанных с регламентацией труда муниципальных служащих. Эти недочеты связаны с содержанием функций органов муниципального самоуправления и, как следствие, с содержанием должностных инструкций муниципальных служащих ГО «Город Калининград», положений о структурных подразделениях.

\section{Путь решения}

Необходим дифференцированный подход к кадровому обеспечению муниципального управления [16]. Должностные инструкции должны стать базовым, регулирующим документом для оценки эффективности деятельности муниципального служащего.

В заключение необходимо отметить, что анализ организации труда служащих администрации ГО «Город Калининград» позволил выявить основные проблемы в данной сфере деятельности органа местного самоуправления и сделать практические предложения, направленные на их решение:

Повышение эффективности организации труда предполагает совершенствование всех элементов рабочего процесса. Наиболее критические недостатки отмечены в следующих аспектах:

Выявлены проблемы действующей организационной структуры управления (высокая степень централизации функций управления; дублирование указаний на среднем и нижнем уровнях управления, неоптимальная численность отдельных отделов и управлений). Конкретные мероприятия:

- реорганизация действующей ОСУ направлена на то, чтобы путем совершенствования системы управления повысить эффективность работы администрации, при этом главными факторами улучшения являются рост производительности труда, ускорение 
технического развития, кооперация в принятии и реализации управленческих решений и т.д.

- внесение изменений в действующее штатное расписание администрации, введение ряда новых должностей, а также проведение ряда сокращений и перемещений работников (по итогам аттестации).

- налаживание горизонтальных связей между управления и отделами (проведение совместных семинаров, корректировка должностных инструкций);

- изменение стиля руководства администрацией в сторону его демократизации (повышение степени делегирования полномочий), снижения степени централизации управления;

Отмечен низкий уровень денежного содержания муниципальных служащих, недостаточно эффективная система стимулирования и мотивации прямо связаны с методикой оценки.

Кроме вынесенных в текст статьи предложений, необходимо акцентировать внимание на том, что при оценке эффективности работы муниципальных служащих администрации ГО «Город Калининград» необходимо использовать специализированные методики, научно обоснованные, объективные и прозрачные [17]. В их основе лежат три базовых фактора: время, затрачиваемое на работу, качество ее исполнения, сложность и трудоемкость выполняемой работы. С другой стороны, объективная оценка, основанная на научном подходе, позволит выстроить и более эффективную систему мотивации, будет способствовать карьерному росту успешных муниципальных служащих.

Труд муниципальных служащих администрации используется нерационально, характерна работа в авральном режиме, отсутствие планирования, перезагруженность рабочих кабинетов. В должностных инструкциях не учитываются изменения в содержании работы. Недостаточное материально-техническое обеспечение, жесткий график работы, авралы и незапланированные срочные дела стали причиной сложной психологической обстановки.
Чтобы управленческая деятельность носила позитивный и творческий характер, труд муниципальных служащих должен быть соответствующим образом организован:

- снижение уровня стресса, создание комфортной морально-психологической рабочей обстановки, мотивирующей муниципальных служащих к труду;

- улучшение условий труда: создание более равномерной нагрузки на каждого служащего и соответственно - большая отдача от него;

- экономия рабочего времени приведут к увеличению производительности труда.

Несмотря на солидную нормативную базу, регулирующую муниципальную службу, работа с резервом кадров, особенно руководящего состава органов муниципального самоуправления в ГО «Город Калининград», еще не стала системно организованной.

Острой проблемой остается незначительный оперативный резерв на руководящие должности муниципальной службы. Проблема резерва кадров на муниципальную службу может быть решена на основе добровольного волеизъявления граждан, решениями конкурсных комиссий. Резерв должен формироваться из числа наиболее компетентных и профессионально подготовленных муниципальных служащих, а также лиц, не состоящих на муниципальной службе, потенциал которых может быть использован более эффективно. В этом направлении предстоит решать следующие задачи:

- совершенствование нормативной и методической базы;

- выявление количественной и качественной потребности в оперативном и стратегическом резерве кадров на муниципальную службу;

- выявление через конкурсный отбор специалистов и руководителей, имеющих соответствующий потенциал для зачисления в резерв, в т.ч. на руководящие должности;

- разработка и реализация плана подготовки резерва кадров на муниципальную службу в органах муниципального самоуправления ГО «Город Калининград».

\section{ЛИТЕРАТУРА}

1. Атаманчук Г.В. Сущность государственной службы: история, теория. Закон, практика. М., 2018. С. 162-164

2. Ноздрачев А.Ф. От концепции реформирования государственной службы к новым идеям правового регулирования государственно-служебных отношений в РФ//Модернизация экономики России: итоги и перспективы. М., 2018. С. 184-186

3. Тихомиров Ю.А. Теория компетенции. М.: Юринформцентр, 2019. С. 22-32.

4. Телегин А.С. Государственная гражданская служба Российской Федерации. Пермь, 2015. 144 с.

5. Сергеев А.А. Конституционные принципы государственной службы в российской федерации // Актуальные проблемы права, экономики и управления. 2019. № 11. С. 193-198. С. 196. 
6. Решение Окружного Совета Депутатов г. Калининграда 06 утверждении Положения «0 порядке проведения конкурса на замещение вакантной должности муниципальной службы в органах местного самоуправления городского округа «Город Калининград» от 13 июля 2012 года N234// https://docs. cntd.ru/document/438856406

7. Трифонов В.А. Конституционное право граждан на равный доступ к государственной службе: понятие и сущность // Юридическая наука: история и современность. 2018. № 9. С. 51-56. С. 54.

8. Филатов И.Т., Плюхин Н.В. Спорный вопрос дисциплинарной и административной ответственности // Советское государство и право. 1971. N10. C. 134-135;

9. Хаманева Н.Ю. Проблемы административно-правового регулирования экономических отношений на современном этапе // Административное право и процесс. 2019. N5.

10. Постановление Администрации Г0 «Город Калининград» от 27 января 2015 года N126 «06 утверждении Положения о формировании и подготовке муниципального резерва управленческих кадров в администрации городского округа «Город Калининград» (с изменениями на 30 июля 2020 года)// https://docs.cntd.ru/document/424081435

11. Гришковец А.А. Правовое регулирование государственной гражданской службы в РФ. М. 2018. С. 32-62.

12. Гришковец А.А. Дисквалификация государственных гражданских служащих. С. 1122-1138.

13. Катунина Н.Е. Особенности и проблемы стимулирования качественной работы муниципальных служащих. // http://business.in-texno.ru/rcps/expert

14. Ростовцева Ю.В. Административная ответственность за коррупционные правонарушения в системе государственной службы // Законы России: опыт, анализ, практика. 2019. N3. C. 50;

15. Сергеев А.А. Конституционные принципы государственной службы в российской федерации // Актуальные проблемы права, экономики и управления. 2019. № 11. С. 193-198. С. 196.

16. Пресняков М.В., Чаннов С.Е. Дисциплинарная ответственность гражданских служащих: проблемы нормативной определенности и справедливой дифференциации // Трудовое право. 2019. N8, 9.

17. Виханский 0.С. Стратегическое управление: Учебник. М.: Гардарики, 2018. С. 15.

(с) Захарова Виктория Алексеевна ( zhan.e@bk.ru)

Журнал «Современная наука: актуальные проблемы теории и практики»

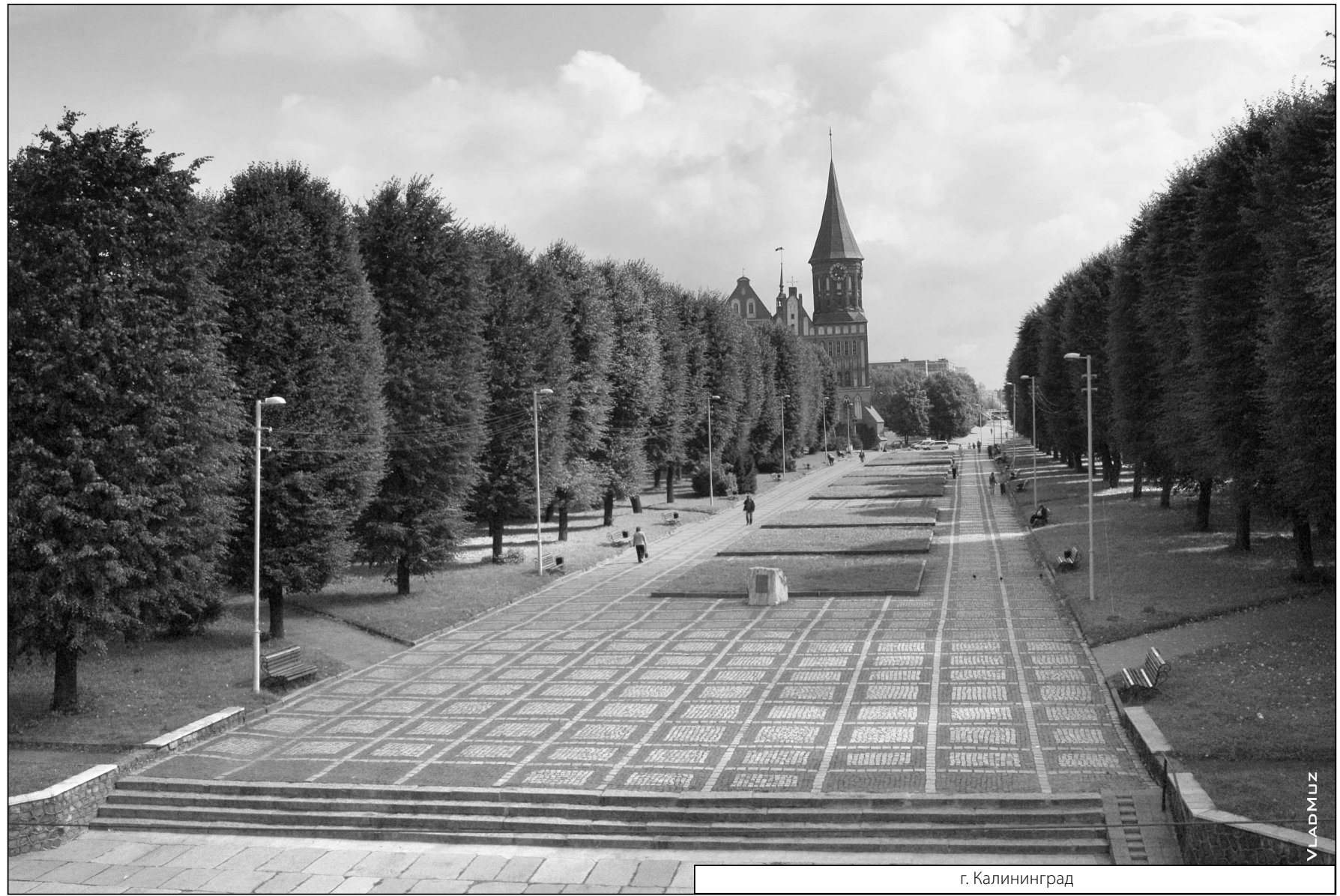

